\title{
For the General Internist: A Summary of Key Innovations
} in Medical Education

\author{
Brita Roy, MD, MPH, MHS' , Shobhina G. Chheda, MD, MPH², Carol Bates, $\mathrm{MD}^{3}$, Kathel Dunn, PhD", \\ Reena Karani, MD, MHPE ${ }^{5}$, and Lisa L. WilleH, $M D^{6}$
}

'Section of General Internal Medicine, Yale University School of Medicine, New Haven, CT, USA; ${ }^{2}$ University of Wisconsin School of Medicine and Public Health, Madison, WI, USA; ${ }^{3}$ Beth Israel Deaconess Medical Center, Harvard Medical School, Boston, MA, USA; ${ }^{4}$ National Library of Medicine, Bethesda, MD, USA; ${ }^{5}$ lcahn School of Medicine at Mount Sinai, New York, NY, USA; ${ }^{6}$ University of Alabama at Birmingham, Birmingham, AL, USA.

We conducted a review of published medical education articles to identify high-quality research and innovation relevant to educators in general medicine. Our review team consisted of six general internists with expertise in medical education and a professional medical librarian. We manually searched 15journals in pairs (a total of 3062 citations) for original research articles in medical education published in 2014. Each pair of reviewers independently rated the relevance, importance, and generalizability of articles on medical education in their assigned journals using a 27-point scale (maximum of 9 points for each characteristic). From this list, each team member independently reviewed the 22 articles that received a score of 20 or higher from both initial reviewers, and for each selected article rated the quality and global relevance for the generalist educator. We included the seven toprated articles for presentation in this review, and categorized the studies into four general themes: continuity clinic scheduling, remediation, interprofessional education, and quality improvement and patient safety. We summarized key findings and identified significant limitations of each study. Further studies assessing patient outcomes are needed to strengthen the literature in medical education. This summary of relevant medical education articles can inform future research, teaching, and practice.

KEY WORDS: medical education; medical education—undergraduate; medical education—graduate; review.

J Gen Intern Med 31(8):941-6

DOI: $10.1007 / \mathrm{s} 11606-016-3669-3$

(c) Society of General Internal Medicine 2016

$\mathrm{E}$ ducators in general medicine must stay abreast of the current literature in order to enhance the training of a competent clinical work force for the complexities of twentyfirst century healthcare. ${ }^{1}$ As the number of medical education publications increases, educators are provided with guidance on ways to improve education for interdisciplinary teams, remediation, clinical experiences, and quality of care. ${ }^{2,3}$ Our

Received October 22, 2015

Revised February 19, 2016

Accepted March 8, 2016

Published online April 15, 2016 aim was to conduct a structured review to identify and summarize the most relevant, high-quality research in medical education published in 2014 to inform general medicine educators involved in undergraduate and graduate medical education and faculty development.

\section{METHODS}

Our team included six general internists with expertise in medical education and a professional medical librarian (KD). Members represented geographically and culturally diverse academic medical centers with senior and junior roles in undergraduate and graduate medical education leadership and faculty development. We included clinician educators involved in teaching, curriculum development, implementation, assessment, and learner evaluation at all stages of medical training.

We manually searched issues published between January and December 2014 by 15 major clinical journals relevant to medical education and with an impact factor $>1.0$, or published by a national organization supporting medical education (Table 1). We considered all original medical education research articles, which were identified by searching tables of contents and by the following PubMed search string limited to the journal name and publication year 2014: (education, medical OR (medical AND (training OR trainees)) OR (clinical AND (skills OR learning OR education))) AND journal article [pt:noexp].

Two reviewers independently reviewed all articles in their assigned journals and rated each on relevance, importance, and generalizability on a nine-point Likert scale ( $1=$ worst, $9=$ best; $\max =27$ ). We defined relevance as timeliness of the topic to medical education and general internal medicine. We defined importance as describing an advancement in the field or providing strong evidence supporting prior literature. We defined generalizability as the potential for application or implementation in any institution. All seven reviewers then read the articles scored in the top third of possible scores (score of $\geq 20$ ) by two reviewers, and assessed each on quality and global appropriateness for our general internist audience. We evaluated quality using the Medical Education Research Study 
Table 1 Primary Journals Manually Searched for Manuscripts Relevant to Medical Education, with Total Number of Full-Length Article Citations Published in 2014

\begin{tabular}{ll}
\hline \hline Journal name & $\begin{array}{l}\text { Number of } \\
\text { citations (2014) }\end{array}$ \\
\hline Academic Medicine & 268 \\
Annals of Internal Medicine & 168 \\
British Medical Journal & 209 \\
BMC Medical Education & 294 \\
Journal of the American Geriatrics Society & 298 \\
Journal of the American Medical Association & 241 \\
Journal of Continuing Education in the Health & 34 \\
Professions & \\
Journal of General Internal Medicine & 277 \\
Journal of Graduate Medical Education & 106 \\
Journal of Hospital Medicine & 145 \\
Lancet & 350 \\
Medical Education & 93 \\
Medical Teacher & 261 \\
New England Journal of Medicine & 266 \\
Teaching and Learning in Medicine & 52 \\
\hline &
\end{tabular}

Quality Instrument (MERSQI), ${ }^{4}$ a reliable scale developed to measure the quality of experimental, quasi-experimental, or observational studies in medical education. ${ }^{5}$ We then individually scored each article using a four-point subjective global rating on its appropriateness for our audience of general internist educators $(3=$ must include, $2=$ strongly consider, $1=$ consider, $0=$ do not include). Any reviewer with a conflict of interest related to a study abstained from scoring and discussion of that article.

Our goal was to present the articles most relevant for a general medicine educator audience and with sound methodology. We thus selected the seven articles with the highest average global rating score that also had an average MERSQI score greater than 8.5. After final selection, we grouped the articles into four general themes to create an organizational framework.

\section{RESULTS}

We reviewed 3062 titles in the issues published in 2014 from the 15 journals we manually searched. Of these, 22 articles received a score greater than 20 from two reviewers for relevance, importance, and generalizability, and were considered for inclusion. Based on average MERSQI scores from all reviewers on these 22 articles, 20 scored above 8.5. The average MERSQI rating was 10.5 (range $7.5-13.1$ ), and the average global rating score was 1.9 (range $0.7-2.7$ ). The seven studies with the highest global rating score from those with MERSQI ratings above 8.5 were included and categorized into four general themes: continuity clinic scheduling, remediation, interprofessional education, and quality improvement and patient safety (Table 2).

\section{Theme 1: Continuity Clinic Scheduling}

The study by Francis, et al., used data collected between September 2010 and May 2011 from 11 community-based and university-based residency programs in the Educational
Innovations Project Ambulatory Collaborative to assess differences in patient satisfaction and diabetes quality of care among three different ambulatory clinic models: (1) traditional (1-2 clinic sessions per week), (2) combination (weekly clinic session in addition to ambulatory blocks), and (3) block (no weekly clinic experience, with an ambulatory block rotation every 1-3 months). ${ }^{6}$ Patient satisfaction was assessed using the 11-item Consumer Assessment of Healthcare Providers and Systems. Resident satisfaction was assessed using the Veterans Affairs Learners' Perception Survey. Quality measures for diabetes included the percentage of diabetic patients with glycosylated hemoglobin $(\mathrm{HbAlc})<8 \%$, blood pressure $<130 /$ $80 \mathrm{mmHg}$, and low-density lipoprotein (LDL) $<100 \mathrm{mg} / \mathrm{dL}$.

The traditional and block models were associated with better patient satisfaction scores compared to the combination model, with more patients feeling that their doctor explained things in a way that was easy to understand $(p<0.001)$, listened carefully to them $(p<0.001)$, gave easy-to-understand instructions $(p<0.001)$, and showed respect for what they had to say $(p<0.001)$. The traditional and block models were also associated with patients reporting follow-up on test results $(p=0.002)$. Overall ratings of the physician were higher for residents in the traditional and block models than the combination model. There was no difference between the traditional and block models. The percentage of patients with $\mathrm{HbAlc}$ $<8 \%$ was associated with higher patient satisfaction scores.

Limitations. This study did not assess whether the program type (e.g. university- or community-based) was associated with the clinic model. Programs were not randomized to the clinic model, and baseline patient satisfaction with the provider was not assessed. The authors did not examine relationships between diabetes quality of care and the ambulatory clinic model.

Implications. This multi-institutional study demonstrated that a traditional or block model was associated with greater overall patient satisfaction than a combination model for continuity clinic. Patient satisfaction was associated with some markers of improved diabetes quality of care.

The study by Heist, et al., is a single-institution study that evaluated the effect of changing from a traditional internal medicine residency clinic scheduling model ( 1 half-day of clinic per week) to a $4+1$ model (4 weeks on rotation without clinic, followed by 1 week in clinic). ${ }^{7}$ The authors compared the first 5 months of outpatient care between 23 first-year residents in the 2012-2013 academic year and 15 first-year residents in the 2011-2012 academic year. Outcomes assessed were the percentage of time that (1) a patient was able to see their primary provider, (2) a provider saw their own patients, (3) a triage encounter (when the patient called the clinic) was handled by the primary provider, and (4) a provider managed his or her own lab results.

Residents had a mean of 17 clinic sessions with 525 visits in the traditional model, compared to 22.5 clinic sessions with 
Table 2 Mean global rating (4-point scale; range 0-3) and quality rating based on the Medical Education Research Study Quality Instrument (MERSQI)

\begin{tabular}{|c|c|c|c|}
\hline$\overline{\text { Article }}$ & Key Points for Practice & $\begin{array}{l}\text { Mean Global } \\
\text { Rating }\end{array}$ & $\begin{array}{l}\text { MERSQI } \\
\text { Score }\end{array}$ \\
\hline \multicolumn{4}{|l|}{ Continuity Clinic Scheduling } \\
\hline $\begin{array}{l}\text { Francis MD, et al., Determinants of Patient Satisfaction } \\
\text { in Internal Medicine Resident Continuity Clinics: } \\
\text { Findings of the Educational Innovations Project } \\
\text { Ambulatory Collaborative }\end{array}$ & $\begin{array}{l}\text { - Traditional and block clinic scheduling models } \\
\text { correlated with patient satisfaction } \\
\text { - Traditional and block clinic scheduling models } \\
\text { correlated with test result follow-up }\end{array}$ & 2.17 & 12.36 \\
\hline $\begin{array}{l}\text { Heist K, et al., Impact of } 4+1 \text { block scheduling on } \\
\text { patient care continuity in resident clinic }\end{array}$ & $\begin{array}{l}\text { - Residents had more clinic sessions and saw more } \\
\text { of their own patients in a } 4+1 \text { block schedule } \\
\text { - Patients had decreased continuity of care }\end{array}$ & 2.0 & 12.0 \\
\hline \multicolumn{4}{|c|}{ - Patents nad decreased contmunty or care } \\
\hline $\begin{array}{l}\text { Guerrasio J, et al., Learner deficits and academic outcomes } \\
\text { of medical students, residents, fellows, and attending } \\
\text { physicians referred to a remediation program, 2006-2012 }\end{array}$ & $\begin{array}{l}\text { - Learners with deficits in clinical reasoning or } \\
\text { mental well-being required more faculty time } \\
\text { for remediation } \\
\text { - A comprehensive, tailored remediation program } \\
\text { for all levels results in successful remediation } \\
\text { for most }\end{array}$ & 2.54 & 10.21 \\
\hline \multicolumn{4}{|l|}{ Interprofessional Education } \\
\hline $\begin{array}{l}\text { Shunk R, et al., Huddle-coaching: a dynamic intervention } \\
\text { for trainees and staff to support team-based care }\end{array}$ & $\begin{array}{l}\text { - A 15-minute interdisciplinary pre-clinic huddle } \\
\text { improves team functioning } \\
\text { - Impact of improved team participation on patient } \\
\text { outcomes is unknown }\end{array}$ & 2.5 & 8.92 \\
\hline $\begin{array}{l}\text { Hoffmann TC, et al., Brief training of student clinicians } \\
\text { in shared decision making: a single-blind randomized } \\
\text { controlled trial }\end{array}$ & $\begin{array}{l}\text { - A 1-hour small group intervention can improve } \\
\text { students' skills and confidence in shared } \\
\text { decision making }\end{array}$ & 2.54 & 13.14 \\
\hline \multicolumn{4}{|l|}{ Quality Improvement and Patient Safety } \\
\hline $\begin{array}{l}\text { Vidyarthi AR, et al., Engaging residents and fellows to } \\
\text { improve institution-wide quality: the first six years of a } \\
\text { novel financial incentive program }\end{array}$ & $\begin{array}{l}\text { - Providing financial incentives to residents for } \\
\text { quality improvement goals resulted in achievement } \\
\text { of } 61 \% \text { of goals } \\
\text { - Having an involved faculty mentor or high } \\
\text { departmental buy-in was associated with } \\
\text { goal achievement }\end{array}$ & 2.33 & 10.93 \\
\hline $\begin{array}{l}\text { Starmer AJ, et al., Changes in medical errors after } \\
\text { implementation of a handoff program }\end{array}$ & $\begin{array}{l}\text { - A comprehensive handoff bundle reduces } \\
\text { medical errors } \\
\text { - The handoff bundle did not impact workflow }\end{array}$ & 2.67 & 12.86 \\
\hline
\end{tabular}

1174 visits in the $4+1$ model, over the same time period. In the $4+1$ model, fewer patients saw their own provider $(72 \%$ vs. $63 \% ; p=0.008)$, but providers saw their own patients more (52\% vs. $37 \% ; p<0.0001)$. There was no difference in resident handling of triage encounters between the two scheduling systems. Residents followed up their own lab results a greater percentage of time in the $4+1$ model $(91 \%$ vs. $76 \% ; p<0.001)$.

Limitations. This single-site study used historical controls, evaluated only the first 5 months of care, and included a low number of residents. Reasons for visits were not evaluated, nor were patient satisfaction or outcomes for management of chronic conditions.

Implications. Residents had more clinic sessions, saw more patients, spent a greater percentage of time seeing their own patients, and more often followed up their patients' lab results in the 4+1 system. However, there was less continuity from the patient perspective, which may have been due to a decreased ability to schedule acute visits with their primary provider. New models of continuity clinic may have educational advantages over traditional models, but may compromise continuity for patients.

\section{Theme 2: Remediation}

The study by Guerrasio, et al., is a single-institution study that identified types of deficits, predictors of poor academic outcomes, and resources required for the remediation of 151 learners (72 medical students, 65 residents, and 14 fellows/ attending physicians) over a 6 -year period. ${ }^{8}$ After self-referral (for attending physicians) or referral due to repeated poor performance, a remediation program faculty member conducted a semi-structured intake interview that addressed ACGME competencies and explored medical knowledge, clinical skills, clinical reasoning, time management/organization, interpersonal skills, communication skills, professionalism, and mental well-being (psychiatric diagnoses, substance abuse, learning disabilities, and psychosocial stressors). A "success team" was formed for the learner with a remediation specialist, and optionally included faculty from the learner's discipline, the program director or student affairs dean, and/or a mental health professional. An individualized learning plan was developed and included deliberate practice, feedback, and reflection. Faculty unfamiliar with students' remediation needs conducted independent reassessments post-remediation. Faculty who were assigned remediation tasks kept a log to record face-toface time spent with the learner. Learners completed a voluntary web-based survey of their remediation experience. 
Most learners had more than one deficit, with a mean (SD) of 2.14 (1.37) deficits for medical students, 1.59 (0.77) for residents, and 1.80 (1.15) for fellows/attendings. Medical knowledge, clinical reasoning, and professionalism were the most common deficits identified. Difficulties with mental wellbeing were significantly more prevalent among medical students $(p=0.03)$. More men were referred $(59 \% ; p=0.04)$, and men were more likely than women to have communication deficits $(p=0.01)$ and difficulties with mental well being $(p=0.06)$. The overall mean (SD) number of hours of faculty face time required for remediation was $18.8(23.8) \mathrm{h} /$ learner. Learners whose deficits included clinical reasoning $(20 \mathrm{~h}$; $p<0.001)$ or mental well-being ( $9 \mathrm{~h} ; p=0.03$ ) required significantly more faculty time than learners without these deficits. Fourteen $(9 \%)$ learners were placed on probation during remediation; poor professionalism was the only predictor of being placed on probation $(p<0.001)$. At the close of the study, $90 \%$ of the participants were in good standing. A total of 120 (79\%) participants responded to the survey, with the majority agreeing or strongly agreeing that the program had helped them address challenges or gain skills that would help them succeed.

Limitations. This was a single-institution study with a program dedicated to underperforming learners. There may have been bias in the misclassification of deficits, and the variability in the membership of the "success team" may have affected individual outcomes. Other factors that were not identified may have also predicted faculty time required for remediation (such as learner willingness to participate).

Implications. This is the largest and most comprehensive study of remediation of medical learners to date. Remediation of struggling learners requires substantial resources but can be effective. A better understanding of the components of the process that are most effective may be of assistance in streamlining faculty time/efforts.

\section{Theme 3: Interprofessional Education}

The paper by Shunk, et al., reports results from a single VA institution that developed a training program to coach trainees and clinic staff on pre-clinic team huddle practices in (1) working together as interdependent team members (team coherence), (2) being physically present and participating in huddling, and (3) using skills such as distributive leadership, active listening, negotiation, and conflict resolution to support effective teamwork. ${ }^{9}$ They developed Patient Aligned Care Teams (PACTs), comprising a registered nurse (RN), licensed vocational nurse (LVN), and a medical clerk working with trainee triads consisting of two second-year internal medicine residents and one second-year nurse practitioner student. The huddle training program was developed with a conceptual framework of process, relational, contextual, and organizational factors, which were addressed by a combination of didactic presentations, small-group skill-building, and reflective sessions including a 1-day retreat and reinforcement through coaching. Huddle coaches were physician and nurse practitioner preceptors who received faculty development training. Teams were expected to huddle for 15 minutes prior to each clinic session.

Program evaluation included feedback on the retreat and on individual teaching sessions, huddle checklists completed by huddle coaches, a qualitative assessment of end-of-year interviews, and scores on a 31-item Team Development Survey evaluating perceived team member cohesiveness, communication, role clarity, and goals. The checklists demonstrated improvement in attendance over time, though $65 \%$ of completed checklists noted the absence of at least one team member. Qualitatively, trainees stated that they enjoyed the huddle experience, they referred to other team members by name, and teams became more functional over time, but that scheduling difficulties and staff turnover negatively impacted huddles. Team Development Survey scores improved over the course of 6 months from a mean of 59.4 to 64.6 on a 100-point scale.

Limitations. While the evaluation of the program appears to be positive, no statistical tests were performed to assess the significance of trends. The generalizability of the specific team structure may be limited, as other sites may have different staff functions and may not have nurse practitioner trainees.

Implications. This interprofessional pre-clinic huddle training intervention improved team coherence and participation. The degree to which the program achieved its stated goal of improving effective teamwork and the effect on patient outcomes is unknown.

The study by Hoffman, et al., evaluates the effectiveness of a 1-h small-group intervention in improving student clinicians' shared decision-making skills. This was a two-institution, single-blinded randomized study, with 100 (93\% of eligible) interprofessional participants, including third-year medical students, final-year occupational therapy honors students, and postgraduate physiotherapy students. ${ }^{10}$ Both study arms received a book chapter on shared decision making, and the intervention group additionally received a 1-h tutorial that included a five-step framework for communicating evidence and a facilitated critique of a pre-recorded modeled role-play on shared decision making. Two weeks later, all participants were paired and videotaped while performing role-plays of a physician-patient encounter that required evidence-based decision making. One author, who was blinded to group allocation, rated the students' role-play from the video recordings. The primary outcome of student skills in shared decision making was rating using the OPTION (Observing Patient Involvement) scale and Assessing Communication about Evidence and Patient Preferences (ACEPP) tool. The secondary outcome, attitudes towards patient and clinical involvement in consultations and confidence in communication with patients about evidence, was rated using a confidence scale created by 
the authors and the Patient Practitioners Orientation Scale (PPOS).

Mean between-group differences in post-intervention scores in shared decision making (18.9 improvement in OPTION, $p<0.001$; 0.9-point improvement in ACEPP; $p<0.001)$ and confidence in facilitating shared decision making (13.1; $p<0.001)$ were better in the intervention group, with no significant change in the caring component of the PPOS $(0.08 ; p=0.4)$.

Limitations. The study limited its follow-up to only 2 weeks after the educational intervention. Pairs of students participated in the role-play, and not standardized or actual patients. Relationships between discipline and outcomes were not assessed.

Implications. The critical skill of shared decision making may be improved using a short interprofessional small-group educational intervention.

\section{Theme 4: Quality Improvement and Patient Safety}

The paper by Vidyarthi, et al., describes and evaluates the first 6 years of a quality improvement (QI) incentive program for residents and fellows at a single institution. ${ }^{11}$ Since 2001, the institution has had an incentive award program for non-physician staff towards achieving patient safety and quality goals; in FY 2007, a variant of this program was added for residents and fellows. The initial goals were "all-program goals" consistent with those already established for staff, phase 2 goals were both relevant to the strategic plan and selected through trainee surveys, and phase 3-or "program-specific goals" - were added by interested training programs. As each goal was met, eligible trainees would receive $\$ 400$; due to the collective nature of the all-program goals, the trainees were evaluated as one cohort.

Data were collected across 18 all-program goals in the domains of patient satisfaction (single item from Press Ganey), quality/safety (Joint Commission core measures from chart abstraction, administrative databases, and Press Ganey), and operation/utilization (such as documentation standards or lab utilization). Trainees received a quarterly scorecard containing data pertinent to each goal.

A total of 5275 residents and fellows participated in allprogram goals over 6 years. In the 3 years of program-specific goal implementation, 16 of 18 training programs (540 total trainees) participated. Trainees received an average of $\$ 800$, achieving 11 of 18 (61\%) all-program goals and 28 of 37 (76\%) program-specific goals. An average of $\$ 724,450$ per fiscal year was paid as trainee bonuses. Trainees were more likely to achieve goals that had an involved faculty mentor, were perceived by trainees as having value, and had high-level departmental buy-in. Some successful training program-specific projects had previously been unsuccessful for the institution.

Limitations. This was not designed as a research study, and the assessment strategy was overlaid on the program. As there was no control arm, confounders, including the programmatic support for QI, were not accounted for. Knowledge, skills, attitudes, and competence in QI among trainees was not measured.

Implications. Providing financial incentives for trainees may result in higher rates of achieving institutional QI goals.

The study by Starmer, et al., evaluated the effect of a systems-based intervention to improve resident handoffs on communication and patient safety in inpatient units at nine academic pediatric residency programs in the U.S. and Canada. No site had a handoff program at baseline. ${ }^{12}$ The sevenelement handoff bundle (including a mnemonic as an anchor for oral and written handoffs, a 2-h workshop on handoff and communication skills, a 1-h role-play and simulation session for practicing workshop skills, a computer module to allow for independent learning, a faculty development program, direct observation tools to provide residents feedback, and a process/ culture change campaign with sustainability materials) was integrated into workflow and patient documentation systems at each site for a 6-month period.

A total of $875(95.4 \%)$ residents participated in the study. A comparison of 5516 pre-intervention and 5224 postintervention patient admissions showed a reduction in the rates of medical errors (preventable failures in processes of care) of $23 \%$ (24.5 vs. $18.8 / 100$ admissions, $p<0.001)$ and a reduction in preventable adverse events of $30 \%$ (4.7 vs. 3.3/100 admissions, $p<0.001)$. No significant changes were observed in duration of oral handoffs or resident workflow.

Limitations. This study focused on pediatric inpatient units, and thus its applicability to other disciplines and settings is unknown. Bundling of several educational and process changes prevents a determination of the elements that were most impactful.

Implications. A multi-pronged handoff program addressing miscommunication significantly reduced medical errors and preventable adverse events, without increasing the duration of oral handoffs.

\section{DISCUSSION}

Our review of the 2014 literature relevant to general internal medicine educators highlights seven articles related to continuity clinic scheduling, remediation, interprofessional education, and quality improvement/patient safety. We present studies of high quality and with relevance to general internist medical educators in today's teaching and practice environment.

We identified many articles of importance in the 2014 literature, such as those on primary care residency choice, burnout, humanism and emotional intelligence, cost consciousness, simulation, and clinical reasoning. ${ }^{13-25}$ Compared to our review of the 2013 literature relevant to general 
medicine educators, ${ }^{26}$ we found more multi-institutional studies of high quality. Similar to last year, resident continuity clinic and handoffs were areas of focus. We were encouraged by the growing number of studies on interprofessional education, reflecting the national shift towards collaborative patientcentered medical homes and related care structures, but found little evidence regarding the impact on patient outcomes. ${ }^{14,16,19,25}$ We also found descriptive studies on use of the milestone-based learner assessments. ${ }^{18}$ Our selection process prioritized those most relevant, important, and generalizable, and with greatest methodological quality, for our audience of general internist educators.

Although we reviewed articles on a wide variety of topics and used a structured process to identify high-impact articles for general medicine educators, our study has limitations. We excluded some high-quality studies because they were less globally applicable to our general medicine educator audience. Though we present three multi-institutional studies, the majority of articles reviewed involved single institutions and nonrandomized designs, introducing selection bias. We have discussed the limitations regarding the interpretation and scope of results for each included study. Finally, our review team comprised educators from diverse geographical regions, academic rank, and educational roles. However, faculty from community-based programs and non-physician clinicians were not represented. Article selection, therefore, may be biased towards educators at academic medical centers.

\section{CONCLUSION}

The articles presented may help general medicine educators stay abreast of current trends in the medical education literature. Further studies assessing patient outcomes are needed to strengthen the literature in medical education. The reviewed studies may inform future research and practice of medical educators.

Acknowledgments: All authors contributed to the selection of studies to include in the review and to the content and revisions of the manuscript. We would also like to acknowledge the contributions of Briar Duffy, MD, who participated in the selection of studies to include in this review.

Corresponding Author: Brita Roy, MD, MPH, MHS; Section of General Internal MedicineYale University School of Medicine, PO Box 208025, New Haven, CT 06520-8025, USA (e-mail: brita.roy@yale.edu).

\section{Compliance with Ethical Standards:}

Conflict of Interest: The authors declare no conflicts of interest.

\section{Funding and Support: None}

Prior Presentations: This was previously presented as the Update in Medical Education during the Society of General Internal Medicine 38th Annual Meeting on April 23, 2015, in Toronto, ON, CA.

\section{REFERENCES}

1. Cooke M, Irby DM, O'Brien BC. Educating physicians: a call for reform of medical school and residency. Vol. 16. John Wiley \& Sons; 2010.

2. Shea JA, Arnold L, Mann KV. A RIME perspective on the quality and relevance of current and future medical education research. Acad Med. 2004;79(10):931-8.

3. Wartman SA. Revisiting the idea of a national center for health professions education research. Acad Med. 2004;79(10):910-7.

4. Reed DA, et al. Association between funding and quality of published medical education research. Jama. 2007;298(9):1002-9.

5. Reed DA, Beckman TJ, Wright SM. An assessment of the methodologic quality of medical education research studies published in The American Journal of Surgery. Am J Surg. 2009; 198(3):442-4.

6. Francis MD, et al. Determinants of patient satisfaction in internal medicine resident continuity clinics: findings of the educational innovations project ambulatory collaborative. J Grad Med Educ. 2014;6(3):470-7.

7. Heist $\mathbf{K}$, et al. Impact of $4+1$ block scheduling on patient care continuity in resident clinic. J Gen Intern Med. 2014;29(8):1195-9.

8. Guerrasio J, Garrity MJ, Aagaard EM. Learner deficits and academic outcomes of medical students, residents, fellows, and attending physicians referred to a remediation program, 2006-2012. Acad Med. 2014;89(2):352-8.

9. Shunk R, et al. Huddle-coaching: a dynamic intervention for trainees and staff to support team-based care. Acad Med. 2014;89(2):244-50.

10. Hoffmann TC, et al. Brief training of student clinicians in shared decision making: a single-blind randomized controlled trial. J Gen Intern Med. 2014;29(6):844-9.

11. Vidyarthi AR, et al. Engaging residents and fellows to improve institutionwide quality: the first six years of a novel financial incentive program. Acad Med. 2014;89(3):460-8.

12. Starmer AJ, et al. Changes in medical errors after implementation of a handoff program. N Engl J Med. 2014;371(19):1803-12.

13. Kost A, et al. Primary care residency choice and participation in an extracurricular longitudinal medical school program to promote practice with medically underserved populations. Acad Med. 2014;89(1):162-8.

14. Olupeliyawa AM, et al. The Teamwork Mini-Clinical Evaluation Exercise (T-MEX): a workplace-based assessment focusing on collaborative competencies in health care. Acad Med. 2014;89(2):359-65.

15. Angus S, et al. What skills should new internal medicine interns have in july? A national survey of internal medicine residency program directors. Acad Med. 2014;89(3):432-5.

16. Greer AG, et al. The status of interprofessional education and interprofessional prevention education in academic health centers: a national baseline study. Acad Med. 2014;89(5):799-805.

17. Piquette D, Mylopoulos M, LeBlanc VR. Clinical supervision and learning opportunities during simulated acute care scenarios. Med Educ. 2014;48(8):820-30.

18. Warm EJ, et al. Entrustment and mapping of observable practice activities for resident assessment. J Gen Intern Med. 2014;29(8): 1177-82.

19. Gonzalo JD, et al. Patient-centered interprofessional collaborative care: factors associated with bedside interprofessional rounds. J Gen Intern Med. 2014;29(7):1040-7.

20. Branch WT Jr, et al. Faculty development to enhance humanistic teaching and role modeling: a collaborative study at eight institutions. J Gen Intern Med. 2014;29(9):1250-5.

21. Fogerty RL, et al. Novel integration of systems-based practice into internal medicine residency programs: the Interactive Cost-Awareness Resident Exercise (I-CARE). Teach Learn Med. 2014;26(1):90-4.

22. Roberts $\mathbf{L}$, et al. Effect of bedside physical diagnosis training on third-year medical students' physical exam skills. Teach Learn Med. 2014;26(1):81-5.

23. Arora VM, et al. Using standardized videos to validate a measure of handoff quality: the handoff mini-clinical examination exercise. J Hosp Med. 2014;9(7):441-6.

24. McAllister C, et al. Relationships within inpatient physician housestaff teams and their association with hospitalized patient outcomes. J Hosp Med. 2014;9(12):764-71.

25. Tofil NM, et al. Interprofessional simulation training improves knowledge and teamwork in nursing and medical students during internal medicine clerkship. J Hosp Med. 2014;9(3):189-92.

26. Roy B, et al. For the general internist: a review of relevant 2013 innovations in medical education. J Gen Intern Med. 2015;30(4):496502 